Revue internationale P.M.E.

\title{
Nos travaux profitent à la société
}

\section{Sophie Reboud}

Volume 29, numéro 1, 2016

URI : https://id.erudit.org/iderudit/1036767ar

DOI : https://doi.org/10.7202/1036767ar

Aller au sommaire du numéro

Éditeur(s)

Editions EMS - In Quarto SARL

ISSN

0776-5436 (imprimé)

1918-9699 (numérique)

Découvrir la revue

Citer ce document

Reboud, S. (2016). Nos travaux profitent à la société. Revue internationale P.M.E., 29(1), 17-17. https://doi.org/10.7202/1036767ar d'utilisation que vous pouvez consulter en ligne.

https://apropos.erudit.org/fr/usagers/politique-dutilisation/ 


\title{
RUBRIQUE SUR LA MOBILISATION DES CONNAISSANCES
}

\author{
Sophie REBOUD \\ Responsable de la rubrique \\ CEREN - Groupe ESC Dijon Bourgogne \\ Honorary Research Fellow - University of Western Australia
}

\section{NOS TRAVAUX PROFITENT Ȧ LA SOCIÉTÉ}

Pour cette quatrième rubrique "Mobilisation des connaissances » nous avons fait appel au professeur Christophe Schmitt, de l'Université de Lorraine. La méthode qu'il nous présente ici permet aux entrepreneurs de formuler leur vision entrepreneuriale et de la faire évoluer au fur et à mesure de son élaboration.

Le témoignage apporté dans cette rubrique montre des chercheurs allant à la rencontre des entrepreneurs, cherchant à comprendre leur mode de raisonnement et à l'accompagner en le formalisant. La mise au point, puis la diffusion de la méthode dans un large tissu économique et pédagogique, en France puis dans de nombreux autres pays, constituent une démarche exemplaire de mobilisation des connaissances profitant à la société.

Encore une fois, comme dans les rubriques précédentes, on voit comment des chercheurs peuvent mettre en cohérence leurs différentes missions, de recherche, d'enseignement et de service à une communauté.

Bonne lecture! 